CLINICAL STUDY

\title{
Assessing adrenal status in patients before and immediately after coronary artery bypass graft surgery
}

\author{
Miguel Debono, Lorcan Sheppard ${ }^{1}$, Sarah Irving $^{1}$, Philip Jackson ${ }^{1}$, Jo Butterworth ${ }^{1}$, Zoe L S Brookes ${ }^{2}$, \\ John Newell-Price, Jonathan J Ross ${ }^{1}$ and Richard J Ross \\ Academic Unit of Endocrinology, Royal Hallamshire Hospital, University of Sheffield, M Floor, Glossop Road, Sheffield S1O 2JF, UK, ${ }^{1}$ Department of \\ Anaesthesia, Northern General Hospital, Sheffield S5 7AU, UK and ${ }^{2}$ Microcirculation Research Group, University of Sheffield S1O 2RX, Sheffield, UK \\ (Correspondence should be addressed to R J Ross; Email: r.j.ross@sheffield.ac.uk)
}

\begin{abstract}
Objective: Patients with cortisol deficiency poorly tolerate any systemic inflammatory response syndrome (SIRS), and may die if not treated with sufficient exogenous glucocorticoids. Controversy surrounds what constitutes a 'normal' adrenal response in critical illness. This study uses conventional tests for adrenal insufficiency to investigate cortisol status in patients undergoing elective coronary artery bypass surgery, a condition frequently associated with SIRS.

Design: A prospective, observational study.

Methods: Thirty patients with impaired left ventricular function (ejection fraction $>23 \%<50 \%$ ) underwent basal ACTH measurement, and a short cosyntropin test $(250 \mu \mathrm{g}$, i.v. $) 1$ week preoperatively, and at $+4 \mathrm{~h}$ following induction of general anaesthesia. Preoperatively, a $30 \mathrm{~min}$ cortisol level post cosyntropin $>550 \mathrm{nmol} / \mathrm{l}$ was taken as a normal response.

Results: Prior to surgery, all patients had a normal response to cosyntropin. Postoperatively, eight patients $(26.7 \%)$ did not achieve stimulated cortisol levels $>550 \mathrm{nmol} / \mathrm{l}$ and the mean peak cortisol postoperatively was lower (1048 vs $730 \mathrm{nmol} / \mathrm{l}$; $P<0.001)$. There was a significant rise in ACTH after surgery (21 vs $184 \mathrm{ng} / \mathrm{l} ; P=0.007$ ) and reduction in $\Delta$-cortisol post cosyntropin (579 vs $229 \mathrm{nmol} / \mathrm{l}$; $P<0.001$ ). There was no change in basal cortisol pre- and post-operatively (447 vs $501 ; P=0.4$ ). All patients underwent routine, uneventful postoperative recovery.

Conclusion: Up to one quarter of patients with a normal cortisol status preoperatively demonstrated a raised ACTH and deficient cortisol response postoperatively. Despite these responses, all patients had uneventful outcomes. These data reinforce the need for caution when interpreting results of endocrine testing following major surgery or in the intensive care environment, and that prognostic value of these results may be of limited use.
\end{abstract}

European Journal of Endocrinology 164 413-419

\section{Introduction}

Cortisol is a critical player in the endocrine response to stress and is essential for survival in critical illness (1). Activation of the hypothalamic-pituitary-adrenal (HPA) axis represents one of several important responses to physiological stresses, such as surgery and critical illness. Despite a large volume of published data on this topic, controversy remains as to the definition of a 'normal' adrenal response, and what is meant by the concept of relative adrenal insufficiency or critical illness-related corticosteroid insufficiency (CIRCI) (2).

In the unstressed subject, cortisol has a distinct circadian rhythm: high on waking and low on going to sleep (3). In contrast, surgery stimulates both the endocrine and immune systems to mount a systemic reaction to the associated injury as part of the healing process and cortisol levels may increase to $830-1400 \mathrm{nmol} / \mathrm{l}$, with phase shifting of the physiological rhythm depending on the degree of surgical stress $(4,5)$. This principally occurs through cytokine regulation of the HPA axis primarily by direct or indirect stimulation of hypothalamic CRH, especially by IL1, IL6, and tumour necrosis factor $\alpha$ (TNF $\alpha$ ), and also by directly affecting the pituitary and adrenal glands (6). To balance the inflammatory response, IL10 acts as an immunosuppressant neutralising pro-inflammatory effects (7). In a subpopulation of patients exposed to cardiopulmonary bypass $(\mathrm{CPB})$, this systemic reaction can propagate a huge pro-inflammatory response, similar to that seen in sepsis. The systemic inflammatory response syndrome (SIRS) describes the clinical manifestation of this response (8) and progression to an advanced stage of SIRS is associated with prolonged cardiovascular support and a high mortality. 
Studies generally show that during surgery the HPA is activated especially after extubation, whereby plasma ACTH levels are increased and are associated with elevated serum cortisol concentrations. Thereafter, plasma levels of ACTH decline rapidly to normal levels, whereas serum cortisol concentrations decrease slowly, reaching high normal values $\sim 48-72 \mathrm{~h}$ after the procedure (9). This has been confirmed in coronary artery bypass graft operations, associated with SIRS consequent to sternotomy and CPB, where basal and stimulated cortisol levels have been correlated with severity of stress, peaking shortly after extubation and being similar to levels during other major surgical procedures and critical illness (10).

It has been stated that adrenal insufficiency is rare in the setting of critical illness (11), but the methods commonly used to make the diagnosis of adrenal insufficiency are not necessarily applicable in the critically ill patient, and the incidence may therefore have been underestimated. In contrast, other authors have reported significantly higher rates of insufficient adrenal response in critical illness (12) especially in those with a prolonged stay in ICU, and in those over 55 years of age (13-15). In view of such conflicting published data, we performed a prospective study to investigate the immediate impact of major surgery on the tests used to diagnose adrenal insufficiency.

\section{Subjects and methods}

\section{Study population}

A prospective, observational study was performed at Sheffield Teaching Hospitals Cardio-Thoracic Surgical Unit and Cardiac Intensive Care Unit to analyse tests for adrenal insufficiency pre- and post-operatively. The study was also set up to examine the impact of lowdose hydrocortisone therapy, and patients were randomised to treatment with a low-dose hydrocortisone infusion or placebo after all tests, assessing each participant's adrenal status, were complete. However, measurement of cortisol levels during the infusion showed no difference between the groups and this data has not been included in the analysis of the 30 patients reported in this article. Thirty consecutive patients, $>17$ years of age with impaired left ventricular function (ejection fraction $>23 \%<50 \%$ ), were recruited. Patients with severe ventricular electrical irritability, congenital or valvular heart disease, cardiac ejection fraction $<23 \%$, systemic corticosteroids within the previous 3 months, severe renal impairment (creatinine $>200 \mu \mathrm{mol} / \mathrm{dl}$ ), asthma, insulin-treated diabetes, those needing emergency cardiac surgery and those with an abnormal cortisol response (peak cortisol $<550 \mathrm{nmol} / \mathrm{l}$ ) after a $250 \mu \mathrm{g}$ cosyntropin test were excluded. These criteria were used in an effort to ensure that as homogenous population as possible was recruited.
The study was approved by the North Sheffield Research ethics committee and all patients gave written informed consent prior to participation in the trial.

\section{Materials and methods}

One week prior to surgery, the patients had basal ACTH and a short cosyntropin test for adrenal function. Immediately prior to surgery, a pulmonary artery flotation catheter (Baxter Healthcare Corp., Irvine, CA, USA) was placed for cardiovascular monitoring. Use of etomidate, which causes reversible inhibition of the adrenal $11 \beta$-hydroxylase, was avoided for anaesthetic induction. Following induction of anaesthesia and sternotomy, patients were placed on CPB during coronary artery grafting and on completion were weaned off CPB. Inotrope support was commenced where necessary as decided by the anaesthetist and surgeon. Patients were then transferred to the CICU, received routine recovery care and had a postoperative cosyntropin test around $4 \mathrm{~h}$ from the time of induction. All operations were complete by this time. The parameters related to surgery were measured: $\mathrm{CPB}$ time, aortic cross-clamping time and total theatre time (Table 1).

The following tests were analysed pre- and postoperatively: basal cortisol, stimulated $30 \mathrm{~min}$ cortisol post cosyntropin (peak cortisol), difference between stimulated and basal cortisol ( $\Delta$-cortisol) post cosyntropin (peak-basal), percentage change in cortisol $(100 \%$ $\times$ peak-basal cortisol/basal cortisol), ACTH, cortisol/ ACTH. A stimulated cortisol level $<550 \mathrm{nmol} / \mathrm{l}$ and a $\Delta$-cortisol $<250 \mathrm{nmol} / \mathrm{l}$ post cosyntropin were taken as abnormal responses, since a normal response is widely regarded as a $30 \mathrm{~min}$ cortisol value $>550 \mathrm{nmol} / \mathrm{l}$ (16-18) and a $\Delta$-cortisol $>250 \mathrm{nmol} / \mathrm{l}$. The latter has been used previously as a criterion for a normal adrenal response in studies investigating the HPA axis during septic shock (19-21). High ACTH levels in the presence of relatively low cortisol values, that is a low cortisol/ ACTH, may be indicative of primary adrenal insufficiency, while low to normal ACTH levels in the presence of low cortisol values are principally indicative of secondary adrenal insufficiency $(22,23)$.

The following were deemed indicative of an adverse event: tachycardia (sustained $(>5 \mathrm{~min})$ pulse rate $>130 \%$ baseline), hypertension (sustained (>5 min)

Table 1 Demographic data and peri-operative intensive care parameters in 30 coronary artery bypass surgery patients.

\begin{tabular}{ll}
\hline Mean age (range) & $63(48-83)$ \\
Weight $(95 \% \mathrm{Cl})$ & $84.5(78.4-90.6) \mathrm{kg}$ \\
BMI $(95 \% \mathrm{Cl})$ & $28.5(26.8-30.2) \mathrm{kg} / \mathrm{m}^{2}$ \\
CPB time (range) & $68.4(60.5-76.3) \mathrm{min}$ \\
AXC time (range) & $42.3(37.1-47.5) \mathrm{min}$ \\
Total theatre time (range) & $3.8(3.6-4.0) \mathrm{h}$
\end{tabular}

$\mathrm{CPB}$, cardiopulmonary bypass; AXC, aortic cross-clamping. 
mean arterial pressure $>130 \%$ baseline), hypotension (sustained $(>5 \mathrm{~min}$ ) mean arterial pressure $<70 \%$ baseline), presence of myocardial ischaemia (new, sustained $(>5 \mathrm{~min}$ ) ST changes $>1.0 \mathrm{~mm}$ ST depression/elevation), new arrhythmias and failure to wean from bypass.

\section{Assays}

Total serum cortisol was measured in a Siemens Advia Centaur Cortisol assay: analytical range $5.5-2069 \mathrm{nmol} / \mathrm{l}$; inter-assay coefficient of variation (CV), $6.2 \%$ at $134 \mathrm{nmol} / \mathrm{l}, 5.5 \%$ at $491 \mathrm{nmol} / \mathrm{l}$ and $6.0 \%$ at $837 \mathrm{nmol} / \mathrm{l}$. Normal $0900 \mathrm{~h}$ cortisol reference range was $198-720 \mathrm{mmol} / \mathrm{l}$. Plasma ACTH was measured in a Siemens Immulite 2000 chemiluminescent assay: analytical range $5-1250 \mathrm{ng} / \mathrm{l}$; inter-assay $\mathrm{CV}$ values, $6.4 \%$ at $32.1 \mathrm{ng} / \mathrm{l}, 6.5 \%$ at $478 \mathrm{ng} / \mathrm{l}$. Normal $0900 \mathrm{~h}$ ACTH reference range was $<46 \mathrm{ng} / \mathrm{l}$.

\section{Statistical analysis}

Database management and all statistical analyses were performed using SPSS Version 15.0 (IBM Corporation, Somers, NY, USA) and Microsoft Excel Version 2007. Rates and percentages were calculated for categorical data, and means and 95\% confidence intervals (CIs) for continuous data. For continuous variables, differences within the same group were analysed by the paired sample $t$-test. Correlation analyses were determined by calculating Pearson's $r$ coefficient. A significant result was taken as $P<0.05$.

\section{Results}

Thirty patients were recruited and all patients completed the study. Demographic data are shown in Table 1.

\section{Basal and $250 \mu$ cosyntropin-stimulated cortisol levels}

Preoperatively, all patients achieved a $30 \mathrm{~min}$ cortisol level $>550 \mathrm{nmol} / \mathrm{l}$ after the cosyntropin test, thereby excluding adrenal insufficiency. Mean (95\% CI) preoperative basal cortisol and cosyntropin-stimulated cortisol levels were $447.0(385.4-508.6) \mathrm{nmol} / \mathrm{l}$ and 1048 (945-1151) nmol/l respectively. There was no significant difference in the basal postoperative mean cortisol level 501 (393-609) nmol/l compared with preoperative levels $(P=0.4)$, but there was a significant difference in the postoperative cosyntropin-stimulated mean cortisol 730.2 (632.2-828.2) nmol/l $(P<0.001)$ compared to the preoperative value. Eight patients $(26.7 \%)$ had stimulated cortisol levels $<550 \mathrm{nmol} / \mathrm{l}$ postoperatively (Fig. 1).
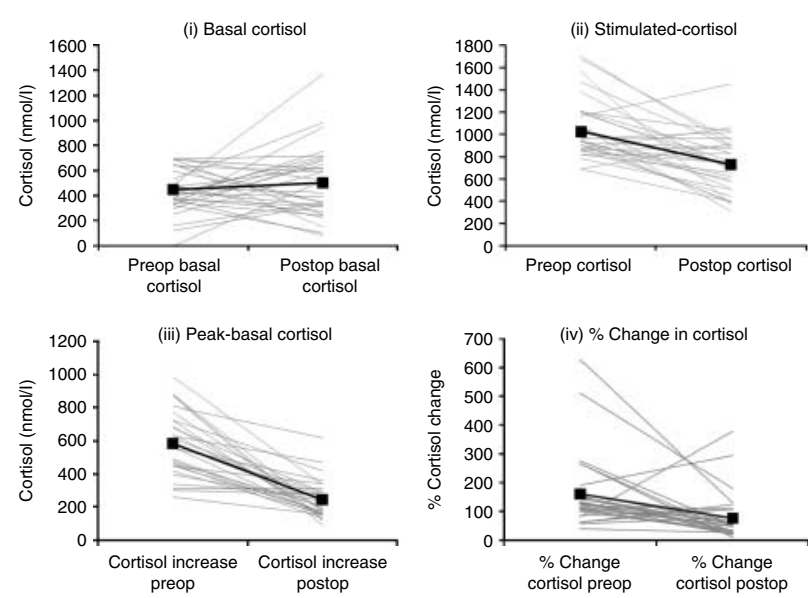

Figure 1 Changes between mean $( \pm 95 \% \mathrm{Cl})$ pre- and postoperative measurements of (i) basal cortisol (447 (385-509) vs 501 (393-609) nmol/l; $P=0.4$ ), (ii) stimulated 30 min cortisol post cosyntropin (peak cortisol) (1048 (945-1151) vs 730.1 (632-828) $\mathrm{nmol} / / ; P<0.001$ ), (iii) $\Delta$-cortisol post cosyntropin (peak-basal) 579 (504-654) vs 229 (170-288) nmol//; $P<0.001$ ), (iv) percentage change in cortisol $(100 \% \times$ peak-basal cortisol/basal cortisol) 161 $(112-210)$ vs 77 (45-107); $P=0.002)$ estimated by paired sample $t$-test. Bold lines (mean); light lines (individual values).

No correlation was found between basal or stimulated pre- and post-operative cortisol values but there was a significant strong correlation between postoperative basal and stimulated cortisol levels ( $r=0.841 ; P<0.001)$ (Fig. 2).

All patients had a $\Delta$-cortisol, that is the difference between stimulated cortisol (peak) and basal cortisol, $>250 \mathrm{nmol} / \mathrm{l}$ preoperatively while $17 / 30$ (57\%) had a $\Delta$-cortisol $<250 \mathrm{nmol} / \mathrm{l}$ postoperatively. The mean

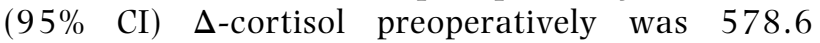
(503.7-653.5) nmol/l, with a mean percentage change of $161 \%(112-210)$, while that postoperatively was $229.1(170.4-287.8) \mathrm{nmol} / \mathrm{l}$ with a mean percentage change of $76.5 \%(45.5-107.5)$. A significant difference was shown when comparing preand post-operative mean $\Delta$-cortisol $(P<0.001)$, and
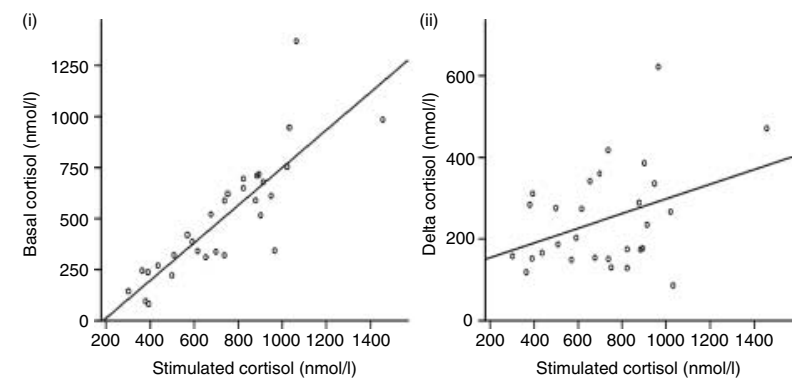

Figure 2 Pearson's correlation between postoperative (i) basal cortisol and stimulated (peak) cortisol post cosyntropin ( $r=0.84$; $P<0.001$ ) and (ii) $\Delta$-cortisol and stimulated (peak) cortisol post cosyntropin $(r=0.4 ; P=0.04)$. These correlations potentially highlighting lack of adrenal sensitivity to endogenous $A C T H$ and cosyntropin in a number of individuals immediately post CABG. 
pre- and postoperative percentage change in cortisol $(P=0.002)$. Percentage change in cortisol $=100 \% \times$ peak-basal cortisol/basal cortisol (Fig. 1).

There was no correlation between pre- and postoperative $\Delta$-cortisol $(r=0.09 ; P=0.6)$ or percentage change in cortisol levels $(r=0.2 ; P=0.4)$. Analysis of postoperative tests showed a significantly weak correlation between $\Delta$-cortisol and stimulated (peak) cortisol levels ( $r=0.4 ; P=0.04$ ) (Fig. 2).

\section{ACTH and cortisol/ACTH ratios}

Mean (95\% CI) basal ACTH levels preoperatively were $21.1 \mathrm{ng} / \mathrm{l}$ (16.4-25.8), all were within the normal reference range. Compared with preoperative levels, there was a significant increase in ACTH levels to 183.8 (71.9-295.7) ng/l $(P=0.007)$ postoperatively. The mean basal cortisol/ACTH ratio preoperatively was 24.0 (21.24-26.76) and this was significantly different $(P<0.001)$ to the postoperative mean level of 8.9 (6.08-11.7) (Fig. 3).

Both preoperative ACTH and postoperative ACTH correlated significantly with preoperative $(r=0.7$; $P<0.001)$ and postoperative $(r=0.433 ; P=0.017)$ basal cortisol levels respectively but the correlation was weaker postoperatively (Fig. 4).

\section{Patient outcomes}

Only one patient had an episode of sustained hypotension. His postoperative basal cortisol was $245 \mathrm{nmol} / \mathrm{l}$, stimulated cortisol $364 \mathrm{nmol} / \mathrm{l}, \Delta$-cortisol $119 \mathrm{nmol} / \mathrm{l}$ and cortisol/ACTH ratio 3.61. He remained intubated for $17 \mathrm{~h}$ and was on inotropes for $21 \mathrm{~h}$. He was not given corticosteroids and was discharged from CICU after $<24 \mathrm{~h}$. This patient had a temperature $>38.3{ }^{\circ} \mathrm{C}$ and a raised WCC of $12.1 \times 10^{3} ; 11 / 22$ patients with a response to cosyntropin $>550 \mathrm{nmol} / \mathrm{l}$ and $5 / 8$ patients with a response $<550 \mathrm{nmol} / \mathrm{l}$ required inotropes. One patient had sustained tachycardia, one other patient had sustained hypertension and two patients had ischaemic episodes. One patient had sustained tachycardia, hypertension and an ischaemic episode.
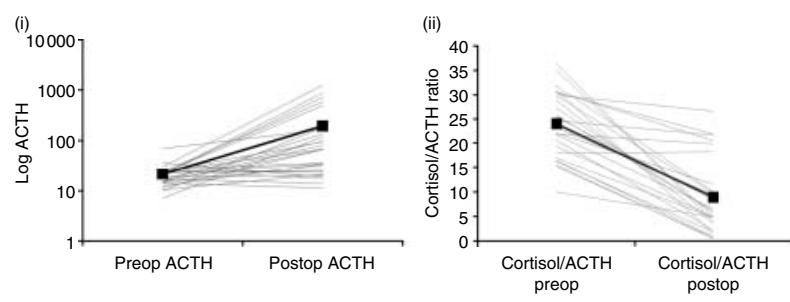

Figure 3 Changes between mean $(95 \% \mathrm{Cl})$ pre- and post-operative measurements of (i) ACTH (21 (16-26) vs 184 (72-296) ng/l; $P=0.007)$ and (ii) cortisol/ACTH ratio (24 (21-27) vs $9(6-12)$; $P<0.001)$ estimated by paired sample $t$-test. Bold lines (mean); light lines (individuals).
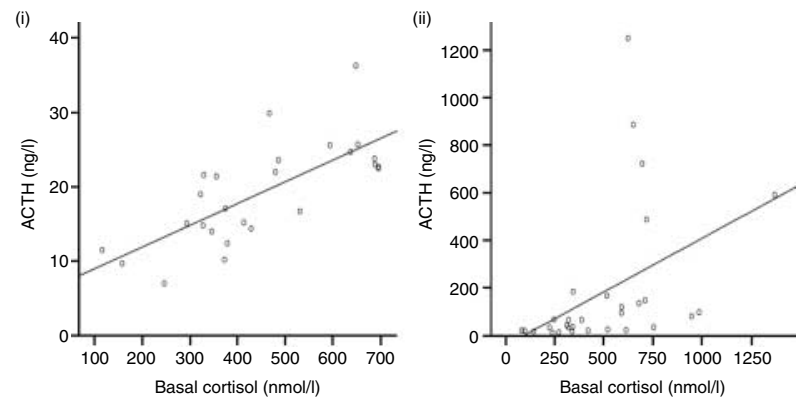

Figure 4 Pearson's correlation between (i) preoperative ACTH and basal cortisol ( $r=0.7 ; P<0.001)$ and (ii) postoperative ACTH and basal cortisol ( $r=0.433 ; P=0.02)$. These correlations reveal the maintenance of, but slight worsening of, the adrenal response to ACTH postoperatively when compared to preoperative values.

\section{Discussion}

We have shown that up to a quarter of patients with a normal HPA axis preoperatively have a reduced cortisol response to cosyntropin immediately following coronary arterial bypass grafting surgery. The advantage of this study is the demonstration of a normal HPA axis preoperatively. During stressful events, the HPA axis is activated with a resultant increase in ACTH and cortisol levels (24). Cortisol at these levels then exerts its suppressive or anti-inflammatory effects, which are crucial for re-establishing homeostasis. In patients undergoing coronary artery bypass surgery (CABG), cortisol levels around $1200 \mathrm{nmol} / \mathrm{l}$ have been shown to suppress plasma IL6 while significantly increasing plasma IL10 potentiating the anti-inflammatory response (25). Our results differ from previous publications as although ACTH was elevated postoperatively the basal cortisol was not increased and thus the ratio of cortisol to ACTH was reduced. These results may suggest an element of insensitivity to ACTH. Our patients were studied immediately after surgery in contrast to previous studies, which were undertaken at the time of extubation (10).

In studies investigating the adrenal response to critical illness, results have been conflicting and no defined criteria exist. Most publications have adopted the serum cortisol response to the standard cosyntropin test $(250 \mu \mathrm{g}$, i.v. $)$ to characterise patients as 'responders' (those who had an increment of $>250 \mathrm{nmol} / \mathrm{l}$ in serum cortisol) and 'non-responders' (those who had an increment of $<250 \mathrm{nmol} / \mathrm{l}$ in their serum cortisol levels), regardless of their baseline values (19, 20). Other studies evaluated the prognostic value of measuring baseline and cosyntropin-stimulated serum cortisol $(20,26,27)$. Proposed lower thresholds for stress-elevated basal cortisol concentrations vary widely in the literature and it has been proposed that cortisol levels $<414 \mathrm{nmol} / \mathrm{l}$ are in keeping with adrenal insufficiency, while stimulated or non-stimulated levels $>827-940 \mathrm{nmol} / \mathrm{l}$ are unlikely to indicate any 
deficiency $(9,12)$. In the Corticosteroid Therapy for Septic Shock (CORTICUS) study, investigating the use of i.v. hydrocortisone in patients with septic shock, it was shown that hydrocortisone did not significantly improve survival in patients who did not respond to cosyntropin $(\Delta$-cortisol after cosyntropin $<250 \mathrm{nmol} / \mathrm{l})$ (28). Hence, the cosyntropin test was deemed not to be useful in determining which patients should receive hydrocortisone therapy.

This study showed that the adrenal status of patients undergoing major stress during a CABG showed significant changes, with many not achieving the criteria for adrenal sufficiency. All tests were normal prior to surgery but $4 \mathrm{~h}$ postoperatively there was a significant difference in ACTH, cortisol/ACTH ratios and response to cosyntropin. Around $25 \%$ of patients failed to achieve a stimulated cortisol $>550 \mathrm{nmol} / \mathrm{l}$ post cosyntropin and this was not predictable from preoperative tests. An equal number of individuals from those either failing or passing the cosyntropin test required inotropes. Interestingly, there was no significant difference in basal cortisol levels pre- and postoperatively. Previously, it was shown that during CABG maximal cortisol levels were achieved post extubation with maximal stress (10). Adrenal status tests in our patients were performed $4 \mathrm{~h}$ after induction while most patients were still intubated (mean time for extubation $7.2 \mathrm{~h}$ ) and therefore potentially a further rise in cortisol levels may have been expected if the tests were done later. Irrespectively, at this point of the surgical procedure one would have expected mean cortisol levels higher than $501 \mathrm{nmol} / \mathrm{l}$, as measured in our patients. Further, $57 \%$ of patients did not achieve $\Delta$-cortisol $>250 \mathrm{nmol} / \mathrm{l}$ post cosyntropin. The clinical outcome for all these patients was not significantly different from those who did achieve a change in cortisol $>250 \mathrm{nmol} / \mathrm{l}$ and postoperative recovery was uneventful.

A reason for an apparent lower baseline cortisol or stimulated cortisol could be related to these being measured as total cortisol levels. Total cortisol, during major surgery or illness with associated hypoalbuminaemia and low cortisol-binding globulin (CBG), will be low, although free cortisol levels, the fraction of cortisol exerting physiological function, may be normal or high (29). This possibly explains why our patients had a good final outcome, as in general glucocorticoid secretion would have been increased although this was not discernible in this case. Measuring albumin and CBG levels together with estimations of free cortisol in patients undergoing CABG would be useful to help clarify this hypothesis (30). Dilution of proteins, such as CBG and albumin, due to the large amount of fluids given to patients during resuscitation results in a lower level of measured total cortisol. This has previously been reported in patients undergoing CABG (31) in which there was a highly significant correlation between the degree of haemodilution and the percentage rise in the free cortisol fraction.
Potentially, a low baseline cortisol and a low stimulated cortisol could also represent an element of relative adrenal insufficiency or CIRCI. This must have been short lived as all patients recovered from surgery. CIRCI is defined as inadequate corticosteroid activity for the severity of the illness of a patient secondary to either glucocorticoid resistance or HPA axis failure (2). In glucocorticoid resistance, in the face of excessive cytokine production during critical illness, there is a decreased number and binding affinity of glucocorticoid receptors, with post receptor alterations resulting in high cortisol levels (32). Alternatively, various factors have been suggested to influence the HPA axis and confound its evaluation. Both primary and secondary types of adrenal insufficiency have been reported to occur during critical illness $(33,34)$. The results from this study show an impaired adrenal response to cosyntropin with a low cortisol/ACTH ratio postoperatively in keeping with primary adrenal failure. A number of mechanisms may be responsible. TNF $\alpha$ reduces adrenal cortisol synthesis by reducing the sensitivity of adrenal receptors to ACTH resulting in a blunted response to cosyntropin and high ACTH levels with relatively low cortisol levels in the setting of acute illness (35). In addition, corticostatins or defensins produced by cells, such as macrophages and neutrophils, and which may proliferate in a systemic inflammatory response, inhibit the steroidogenic activity of ACTH. They have been shown to increase 20-fold in plasma and 10-fold in adrenal tissue during bacterial infection in rabbits (36). Corticostatins compete with ACTH on their binding sites and exert an inhibitory effect on the adrenal cells resulting in decreased cortisol production $(37,38)$. Another possible mechanism for primary adrenal failure is the release of a number of factors by lipopolysaccharide-stimulated macrophages, similar as to what happens in endotoxic shock, that suppress the steroidogenic response of adrenocortical cells to ACTH, the amount of factors released regulated by lymphokines (39). Furthermore, transforming growth factor- $\beta$, another cytokine derived from monocytes, is also known to inhibit both basal and ACTH-stimulated steroidogenesis (40). A strong correlation identified between postoperative basal and peak cortisol levels and a weaker correlation between ACTH and cortisol postoperatively compared to preoperative values could support this hypothesis. A number of drugs used during surgical procedures are known to affect the HPA axis and direct cortisol production in the adrenal gland. Etomidate, an anaesthetic agent that can reversibly inhibit 11-hydroxylase enzyme and result in decreased cortisol secretion from the adrenal gland (41), was not used in any of the procedures and so does not account for these findings.

Our data confirm that there are limitations in the tests used to assess for adrenal insufficiency in the critically ill patient. Studies have been controversial giving conflicting and unclear results. Baseline serum 
cortisol levels and stimulated cortisol, preferably measuring the free cortisol levels, are most probably the most practical tests although further studies to assess the impact of these tests on outcome and their importance in predicting the benefits of glucocorticoids in these scenarios are necessary.

\section{Declaration of interest}

The authors declare that there is no conflict of interest that could be perceived as prejudicing the impartiality of the research reported.

\section{Funding}

This research was funded in part by the Sheffield Teaching Hospitals Charitable Trust, generously donated by Dr Kath Sherry, FRCA.

\section{Acknowledgements}

The assays were completed by Miss Emma Hall (recipient of Anaesthetic Research Society Vacation Studentship) and Ms Wendy Russell.

\section{References}

1 Blalock JE. A molecular basis for bidirectional communication between the immune and neuroendocrine systems. Physiological Reviews $1989691-32$.

2 Marik PE. Critical illness-related corticosteroid insufficiency. Chest 2009135 181-193. (doi:10.1378/chest.08-1149)

3 Debono M, Ghobadi C, Rostami-Hodjegan A, Huatan H, Campbell MJ, Newell-Price J, Darzy K, Merke DP, Arlt W \& Ross RJ. Modified-release hydrocortisone to provide circadian cortisol profiles. Journal of Clinical Endocrinology and Metabolism 200994 1548-1554. (doi:10.1210/jc.2008-2380)

4 Chernow B, Alexander HR, Smallridge RC, Thompson WR, Cook D, Beardsley D, Fink MP, Lake CR \& Fletcher JR. Hormonal responses to graded surgical stress. Archives of Internal Medicine 1987147 1273-1278. (doi:10.1001/archinte.147.7.1273)

5 McIntosh TK, Lothrop DA, Lee A, Jackson BT, Nabseth D \& Egdahl RH. Circadian rhythm of cortisol is altered in postsurgical patients. Journal of Clinical Endocrinology and Metabolism 198153 117-122. (doi:10.1210/jcem-53-1-117)

6 Turnbull AV \& Rivier CL. Regulation of the hypothalamicpituitary-adrenal axis by cytokines: actions and mechanisms of action. Physiological Reviews 199979 1-71.

7 Oberholzer A, Oberholzer C \& Moldawer LL. Interleukin-10: a complex role in the pathogenesis of sepsis syndromes and its potential as an anti-inflammatory drug. Critical Care Medicine 200230 S58-S63. (doi:10.1097/00003246-200201001-00008)

8 American College of Chest Physicians/Society of Critical Care Medicine Consensus Conference. Definitions for sepsis and organ failure and guidelines for the use of innovative therapies in sepsis. Critical Care Medicine 199220 864-874. (doi:10.1097/ 00003246-199206000-00025)

9 Arafah BM. Hypothalamic pituitary adrenal function during critical illness: limitations of current assessment methods. Journal of Clinical Endocrinology and Metabolism 200691 3725-3745. (doi:10.1210/jc.2006-0674)

10 Widmer IE, Puder JJ, Konig C, Pargger H, Zerkowski HR, Girard J \& Muller B. Cortisol response in relation to the severity of stress and illness. Journal of Clinical Endocrinology and Metabolism 200590 4579-4586. (doi:10.1210/jc.2005-0354)
11 Jurney TH, Cockrell JL Jr, Lindberg JS, Lamiell JM \& Wade CE. Spectrum of serum cortisol response to ACTH in ICU patients. Correlation with degree of illness and mortality. Chest 198792 292-295. (doi:10.1378/chest.92.2.292)

12 Cooper MS \& Stewart PM. Corticosteroid insufficiency in acutely ill patients. New England Journal of Medicine $2003 \mathbf{3 4 8} 727-734$. (doi:10.1056/NEJMra020529)

13 Barquist E \& Kirton O. Adrenal insufficiency in the surgical intensive care unit patient. Journal of Trauma 199742 27-31. (doi:10.1097/00005373-199701000-00006)

14 Kidess AI, Caplan RH, Reynertson RH, Wickus GG \& Goodnough DE. Transient corticotropin deficiency in critical illness. Mayo Clinic Proceedings 199368 435-441.

15 Merry WH, Caplan RH, Wickus GG, Reynertson RH, Kisken WA, Cogbill TH \& Landercasper J. Postoperative acute adrenal failure caused by transient corticotropin deficiency. Surgery 1994116 1095-1100.

16 Lindholm J \& Kehlet H. Re-evaluation of the clinical value of the $30 \mathrm{~min}$ ACTH test in assessing the hypothalamic-pituitaryadrenocortical function. Clinical Endocrinology 198726 53-59. (doi:10.1111/j.1365-2265.1987.tb03638.x)

17 May ME \& Carey RM. Rapid adrenocorticotropic hormone test in practice. Retrospective review. American Journal of Medicine 1985 79 679-684. (doi:10.1016/0002-9343(85)90517-0)

18 Stewart PM, Corrie J, Seckl JR, Edwards CR \& Padfield PL. A rational approach for assessing the hypothalamo-pituitaryadrenal axis. Lancet 19881 1208-1210. (doi:10.1016/S01406736(88)92020-X)

19 Rothwell PM, Udwadia ZF \& Lawler PG. Cortisol response to corticotropin and survival in septic shock. Lancet 1991337 582-583. (doi:10.1016/0140-6736(91)91641-7)

20 Annane D, Sebille V, Troche G, Raphael JC, Gajdos P \& Bellissant E. A 3-level prognostic classification in septic shock based on cortisol levels and cortisol response to corticotropin. Journal of the American Medical Association 2000283 1038-1045. (doi:10. 1001/jama.283.8.1038)

21 Annane D, Maxime V, Ibrahim F, Alvarez JC, Abe E \& Boudou P. Diagnosis of adrenal insufficiency in severe sepsis and septic shock. American Journal of Respiratory and Critical Care Medicine 2006174 1319-1326. (doi:10.1164/rccm.200509-13690C)

22 Besser GM, Cullen DR, Irvine WJ \& Landon J. Plasma corticotrophin levels in primary and secondary adrenocortical insufficiency. Journal of Endocrinology 196943 x-xi.

23 Besser GM, Cullen DR, Irvine WJ, Ratcliffe JG \& Landon J. Immunoreactive corticotrophin levels in adrenocortical insufficiency. BMJ 19711 374-376. (doi:10.1136/bmj.1.5745.374)

24 Ho JT, Al-Musalhi H, Chapman MJ, Quach T, Thomas PD, Bagley CJ, Lewis JG \& Torpy DJ. Septic shock and sepsis: a comparison of total and free plasma cortisol levels. Journal of Clinical Endocrinology and Metabolism 200691 105-114. (doi:10. 1210/jc.2005-0265)

25 Yeager MP, Rassias AJ, Fillinger MP, Discipio AW, Gloor KE, Gregory JA \& Guyre PM. Cortisol antiinflammatory effects are maximal at postoperative plasma concentrations. Critical Care Medicine 2005 33 1507-1512. (doi:10.1097/01.CCM. $0000164565.65986 .98)$

26 Arlt W, Hammer F, Sanning P, Butcher SK, Lord JM, Allolio B, Annane D \& Stewart PM. Dissociation of serum dehydroepiandrosterone and dehydroepiandrosterone sulfate in septic shock. Journal of Clinical Endocrinology and Metabolism $2006 \mathbf{9 1}$ 2548-2554. (doi:10.1210/jc.2005-2258)

27 Sam S, Corbridge TC, Mokhlesi B, Comellas AP \& Molitch ME. Cortisol levels and mortality in severe sepsis. Clinical Endocrinology 200460 29-35. (doi:10.1111/j.1365-2265.2004.01923.x)

28 Sprung CL, Annane D, Keh D, Moreno R, Singer M, Freivogel K, Weiss YG, Benbenishty J, Kalenka A, Forst H, Laterre PF, Reinhart K, Cuthbertson BH, Payen D \& Briegel J. Hydrocortisone therapy for patients with septic shock. New England Journal of Medicine 2008358 111-124. (doi:10.1056/NEJMoa071366) 
29 Hamrahian AH, Oseni TS \& Arafah BM. Measurements of serum free cortisol in critically ill patients. New England Journal of Medicine 2004350 1629-1638. (doi:10.1056/NEJMoa020266)

30 Roth-Isigkeit AK, Dibbelt L \& Schmucker P. Blood levels of corticosteroid-binding globulin, total cortisol and unbound cortisol in patients undergoing coronary artery bypass grafting surgery with cardiopulmonary bypass. Steroids $2000 \mathbf{6 5}$ 513-520. (doi:10.1016/S0039-128X(00)00133-1)

31 Taylor KM, Bain WH, Jones JV \& Walker MS. The effect of hemodilution on plasma levels of cortisol and free cortisol. Journal of Thoracic and Cardiovascular Surgery 197672 57-61.

32 Molijn GJ, Spek JJ, van Uffelen JC, de Jong FH, Brinkmann AO, Bruining HA, Lamberts SW \& Koper JW. Differential adaptation of glucocorticoid sensitivity of peripheral blood mononuclear leukocytes in patients with sepsis or septic shock. Journal of Clinical Endocrinology and Metabolism $1995 \mathbf{8 0}$ 1799-1803. (doi:10. 1210/jc.80.6.1799)

33 Prigent H, Maxime V \& Annane D. Science review: mechanisms of impaired adrenal function in sepsis and molecular actions of glucocorticoids. Critical Care 20048 243-252. (doi:10.1186/ cc2878)

34 Bornstein SR. Predisposing factors for adrenal insufficiency. New England Journal of Medicine 2009360 2328-2339. (doi:10. 1056/NEJMra0804635)

35 Jaattela M, Ilvesmaki V, Voutilainen R, Stenman UH \& Saksela E. Tumor necrosis factor as a potent inhibitor of adrenocorticotropininduced cortisol production and steroidogenic P450 enzyme gene expression in cultured human fetal adrenal cells. Endocrinology 1991128 623-629. (doi:10.1210/endo-128-1-623)
36 Tominaga T, Fukata J, Hayashi Y, Satoh Y, Fuse N, Segawa H, Ebisui O, Nakai Y, Osamura Y \& Imura H. Distribution and characterization of immunoreactive corticostatin in the hypothalamic-pituitary-adrenal axis. Endocrinology 1992130 1593-1598. (doi:10.1210/en.130.3.1593)

37 Tominaga T, Fukata J, Naito Y, Nakai Y, Funakoshi S, Fujii N \& Imura H. Effects of corticostatin-I on rat adrenal cells in vitro. Journal of Endocrinology 1990125 287-292. (doi:10.1677/joe.0. 1250287)

38 Solomon S, Hu J, Zhu Q, Belcourt D, Bennett HP, Bateman A \& Antakly T. Corticostatic peptides. Journal of Steroid Biochemistry and Molecular Biology 199140 391-398. (doi:10.1016/0960-0760 (91)90206-K)

39 Mathison JC, Schreiber RD, La Forest AC \& Ulevitch RJ. Suppression of ACTH-induced steroidogenesis by supernatants from LPS-treated peritoneal exudate macrophages. Journal of Immunology $19831302757-2762$.

40 Hotta M \& Baird A. Differential effects of transforming growth factor type beta on the growth and function of adrenocortical cells in vitro. PNAS $1986 \mathbf{8 3} 7795-7799$. (doi:10.1073/pnas.83. 20.7795)

41 Wagner RL, White PF, Kan PB, Rosenthal MH \& Feldman D. Inhibition of adrenal steroidogenesis by the anesthetic etomidate. New England Journal of Medicine 1984310 1415-1421. (doi:10. 1056/NEJM198405313102202)

Received 6 December 2010

Accepted 22 December 2010 